\title{
Examination of Escherichia coli from poultry for selected adhesin genes important in disease caused by mammalian pathogenic E. coli
}

\author{
P. Stordeur ${ }^{\text {a,* }}$, D. Marlier ${ }^{\mathrm{b}}$, J. Blanco ${ }^{\mathrm{c}}$, E. Oswald ${ }^{\mathrm{d}}$, \\ F. Biet ${ }^{\mathrm{e}}$, M. Dho-Moulin ${ }^{\mathrm{f}}$, J. Mainil ${ }^{\mathrm{a}}$ \\ ${ }^{a}$ Chaire de Bactériologie et de Pathologie Bactérienne, Faculté de Médecine Vétérinaire, \\ Université de Liège, Campus du Sart Tilman, Bât B43a, Liège B4000, Belgium \\ ${ }^{\mathrm{b}}$ Clinique Aviaire et Cunicole, Faculté de Médecine Vétérinaire, Université de Liège, \\ Campus du Sart Tilman, Bât B42, Liège B4000, Belgium \\ ${ }^{\mathrm{c}}$ Laboratorio de Referencia de E. coli, Departamento de Microbiologia e Parasitologia, \\ Faculdad de Veterinaria, Universidad de Santiago de Compostela, Lugo E27002, Spain \\ ${ }^{\mathrm{d}}$ Laboratoire INRA-associé de Microbiologie Moléculaire, Ecole Nationale Vétérinaire, \\ Toulouse F31076, France \\ 'Sanders Aliments, Laboratoire d'Analyses Vétérinaire, Laval F53014, France \\ ${ }_{\mathrm{f}}^{\mathrm{f}}$ Station de Pathologie Aviaire et de Parasitologie, Centre INRA de Tours, Nouzilly F37380, France \\ Received 12 March 2001; received in revised form 7 August 2001; accepted 6 September 2001
}

\begin{abstract}
A collection of 1601 extraintestinal and intestinal Escherichia coli isolated from chickens, turkeys and ducks, in Belgium, France and Spain, was hybridised with gene probes specific for fimbrial and afimbrial adhesins (F17, F18, S $\langle\mathrm{Sfa} / \mathrm{F} 1 \mathrm{C}\rangle$, Bfp, Afa, Cs31A, Intimin $\langle$ Eae $\rangle$, Aida-1) of intestinal, urinary and invasive $E$. coli of mammals and with a probe specific for the $\mathrm{P}$ (Pap/Prs) fimbrial adhesin of urinary and invasive $E$. coli of mammals and birds. Three hundred and eightythree strains (23.9\%) were P-positive, 76 strains (4.8\%) were Afa-positive, 75 strains $(4.7 \%)$ were F17-positive, 67 strains $(4.2 \%)$ were S-positive, 23 (1.4\%) were Intimin-positive, and all were F18-, Cs31A-, Aida1- and Bfp-negative. The 75 F17-positive strains harboured different major subunit A-encoding gene variants, but the f17Ac variant was the most frequent (52 strains, 69.3\%) and seven strains $(9.3 \%)$ were not typeable. The $f 17 \mathrm{G}$ gene variant coding for the GII adhesin was the most frequent (56 strains, $75.0 \%$ ), whereas the $f 17 \mathrm{GI}$ gene variant was present in four strains (5\%) and 15 strains $(20.0 \%)$ were not typeable. All Afa-positive strains harboured the afa-8 variant. The 23 Intimin-positive $E$. coli tested positive for the $\beta$-variant (16 strains; 69.6\%) or for the $\gamma$-variant (seven strains; $30.4 \%$ ) of the eae gene. Chicken and turkey E. coli were more frequently probe-positive (43.6 and $43.1 \%$, respectively) than duck E. coli $(31.5 \%)$ and extraintestinal E. coli
\end{abstract}

\footnotetext{
* Corresponding author. Tel.: +32-4-3664062; fax: +32-4-3664122.

E-mail address: p.stordeur@student.ulg.ac.be (P. Stordeur).
} 
were also more frequently probe-positive (48.4\%) than intestinal strains (18.5\%). Different combinations of probe positive hybridisation results were observed in 72 of the 540 probe-positive E. coli $(13.3 \%)$. The most frequent combinations were between AfaE- 8 and F17 probes (47 strains; $8.7 \%$ ) and between $\mathrm{P}$ and $\mathrm{S}$ probes (13 strains; $2.4 \%$ ). Although f17- and afa-8-related DNA sequences can be plasmid-located in mammalian E. coli, they were not in avian E. coli. Besides the $\mathrm{P}$ fimbrial adhesins, F17 and S fimbrial and Afa-VIII and Intimin afimbrial adhesins may thus represent colonisation factors of avian pathogenic E. coli. (C) 2002 Elsevier Science B.V. All rights reserved.

Keywords: Escherichia coli; Adhesins; Gene probes; PCR; Chicken

\section{Introduction}

Escherichia coli are commensal bacteria of the intestine of animals, but some strains are associated with intestinal, respiratory, urinary or invasive infections. Avian pathogenic $E$. coli (APEC) are often associated with other pathogens such as mycoplasma and viruses or with environmental hazards like dust and high concentration of ammonium in the air (Oyetunde et al., 1978; Gross, 1994). The most frequent pathologies in poultry (chickens, turkeys) associated with $E$. coli are systemic infections with lesions of aerosacculitis, pericarditis, perihepatitis, peritonitis and salpingitis. The main route of entry is the respiratory tract after the inhalation of faeces-contaminated dust. The intestine is the most important reservoir of APEC. After an initial multiplication in the upper respiratory tract, the bacteria colonise the air sacs and the lungs. In a second stage of infection, the bacteria reach the blood and colonise the internal organs such as heart, spleen and liver (Dho-Moulin and Fairbrother, 1999).

APEC are restricted to a few important O-serogroups, with $15-61 \%$ of the total number of isolates belonging to serogroups $\mathrm{O} 1, \mathrm{O} 2$ and $\mathrm{O} 78$, but their specific virulence factors have not been completely identified (Babai et al., 1997; Blanco et al., 1998). The colonisation of the respiratory tract is most probably mediated by adhesins, such as the $\mathrm{P}$ fimbriae which are more frequently expressed by septicaemic APEC than by $E$. coli isolated from healthy chickens (Dozois et al., 1992). Type 1 fimbriae are no longer considered important virulence factors. The production of a capsule and of an aerobactin iron-sequestering system, and resistance to the bactericidal activity of complement, represent virulence properties which help the APEC to survive in the blood stream (Ellis et al., 1988; Lafont et al., 1987).

The association between $E$. coli and enteritis in poultry is controversial. Indeed, some enteric virulence properties have been described in a very few isolates, such as production of classical heat-stable and heat-labile enterotoxins (STa and LT), of a verocytotoxin called VT2y (Parreira et al., 1998), or of the attaching/effacing lesion, but no colonisation factor typical of intestinal APEC has yet been reported (Dho-Moulin and Fairbrother, 1999).

The purpose of this study on a large collection of extraintestinal and intestinal E. coli isolated from chickens, turkeys and ducks, in Belgium, France and Spain, was to determine: (1) the prevalence of DNA sequences coding for fimbrial and afimbrial adhesins of intestinal, urinary and invasive $E$. coli of mammals (F17, F18, S $\langle\mathrm{Sfa} / \mathrm{F} 1 \mathrm{C}\rangle, \mathrm{Bfp}, \mathrm{Afa}$, Cs31A, Intimin $\langle$ Eae $\rangle$, Aida1); (2) the association of these sequences with those coding 
for P (Pap/Prs) fimbriae; their localisation on plasmids or on the chromosome and, the subtyping of the adhesin-encoding sequences detected.

\section{Material and methods}

\subsection{Collection of strains}

A collection of 1601 avian E. coli strains isolated from intestine, heart, spleen, liver, air sacs (65\% invasive strains; $13.5 \%$ intestinal strains; $21.5 \%$ strains with no data) of poultry was obtained from three countries (Spain, France and Belgium). Complete case history was available for 971 strains.

\subsection{Gene probe derivation and colony hybridisation}

The F17, F18, Aida1, Bfp and Cs31A probes were derived by restriction of recombinant plasmids and the Afa, Pap, Sfa, Eae, F17GI, F17GII and AfaE-8 probes, as PCR products.

The F17, F18, Afa, Pap, Sfa and Eae probes detect all known f17-, f18-, afa-, pap/prs-, sfalfoc-, and eae-related genes or gene clusters, respectively (Smyth et al., 1994; Bertin et al., 1996a; Donnenberg and Welch, 1996; Johnson, 1997; Mainil et al., 1997, 2000; Adu-Bobie et al., 1998; Le Bouguénec and Bertin, 1999; Nagy and Fekete, 1999; China et al., 1999b; Gérardin et al., 2000; Oswald et al., 2000). The positive controls were strains 25KH9 (F17+) (Lintermans et al., 1988), 107/86 (F18+) (Imberechts et al., 1994), A30 (Afa+) (Le Bouguénec et al., 1992), J96 (Pap+Sfa+) (Blum et al., 1995) and enteropathogenic (EPEC) strain E2348/69 (Eae+) (Jerse et al., 1990).

The F17GI, F17GII, Aida1, Bfp, Cs31A and AfaE-8 probes are specific for their respective genes or gene clusters of origin (Benz and Schmidt, 1989; Martin et al., 1991; Giron et al., 1993; Bertin et al., 1996b; Lalioui et al., 1999). The positive controls were strains 25KH9 (F17GI+) (Bertin et al., 1996b), S5 (F17GII+) (Bertin et al., 1996b), 2787 (Aida1+) (Benz and Schmidt, 1989), E2348/69 (Bfp+) (Jerse et al., 1990), 31A $(\mathrm{Cs} 31 \mathrm{~A}+)($ Martin et al., 1991) and necrotoxigenic (NTEC) strain 239KH89 (AfaE-8+) (Mainil et al., 1997).

The different DNA probe fragments were purified by the Geneclean II kit (Bio 101, Buena Vista, CA) or by the Qiaquick PCR purification kit (Qiagen, Hilden, Germany) and labelled with $\left[\alpha_{-}{ }^{32} \mathrm{P}\right] \mathrm{dCTP}$ by random priming using the dCTP-labelling beads (Ready-togo, Pharmacia, Uppsala, Sweden). Labelled DNA probes were purified with MicroconYM30 spin columns (Millipore, Beverly, MA).

The DNA colony hybridisation was performed on paper filters (Whatman 541, Belgolabo, Overijse, Belgium) at $65{ }^{\circ} \mathrm{C}$ (Mainil et al., 1997). The negative control for all probes was the HS strain isolated from the faeces of an asymptomatic human (O'Brien et al., 1982).

\subsection{Family PCR reaction}

The F17 probe-positive strains were confirmed by a family PCR which detects all the four variants of the f17A gene coding for the major subunit (Bertin et al., 1996b). The 
control strains were 25KH9 (f17Aa variant) (Lintermans et al., 1988), S5 (f17Ab variant) (El Mazouari et al., 1994), 31A (f17Ac variant) (Bertin et al., 1996a), and 111KH86 (f17Ad variant) (Bertels et al., 1989).

\subsection{Subtyping of F17-, Afa- and Eae-positive strains}

F17-, Afa- and Eae-positive strains were further studied to identify the gene variants coding for these adhesins.

F17-positive strains were subtyped by multiplex PCR assays for the a, b, c, and d variants of the f17A gene, which codes for the major fimbrial subunit and for the two $f 17 \mathrm{G}$ gene variants (I, II) which codes for the fimbrial adhesin (Bertin et al., 1996b). The f17G gene subtyping was completed using the F17GI and F17GII gene probes derived by PCR from the $117 \mathrm{GI}$ and $f 17 \mathrm{GII}$ gene variants. The positive controls were strains $25 \mathrm{KH} 9$ ( $f 17 \mathrm{Aa}$ and f17GI variants), S5 (f17Ab and f17GII variants), 31A (f17Ac variant), and $111 \mathrm{KH} 86$ (f17Ad variant).

Afa-positive strains were subtyped using gene probe and PCR assays for the afaD-8 and afaE-8 genes, wich codes for an invasin and an adhesin, respectively (Lalioui et al., 1999), since previous results (Gérardin et al., 2000) identified the afa variant present in a few avian E. coli as afa-8. The positive control was the NTEC strain 239KH89 (Mainil et al., 1997).

Eae-positive strains were subtyped using a multiplex PCR assay for the $\alpha-, \beta$ - and $\gamma$ variants of the eae gene. Positive controls were the EPEC strain E2348/69 for subtype $\alpha$, the EPEC strain RDEC-1 for subtype $\beta$ and the O157:H7 enterohaemorrhagic (EHEC) strain ATCC43888 for subtype $\gamma$ (China et al., 1999a).

\subsection{Plasmid DNA hybridisation}

Since $f 17$ - and afa-8-related DNA sequences can be plasmid-located in mammalian $E$. coli (Mainil et al., 1997, 1999; Le Bouguénec and Bertin, 1999; Gérardin et al., 2000), plasmid DNA was extracted from the F17- and Afa-positive strains according to the method described by Kado and Liu as modified by Broes et al. (1988). The plasmid bands were separated by electrophoresis $(20 \mathrm{~h}$ at $40 \mathrm{~V})$ in $0.5 \%$ agarose gel. The size ladders were the plasmids from E. coli strain 39R681: 98, 42, 23.9 and 4.6 Mda (Mainil et al., 1997). Gels were treated and hybridised, as described previously (Broes et al., 1988), with the F17 and AfaE-8 probes. The plasmid positive controls were extracted from the NTEC strains 1648S89 and 1649S89 for the F17 and AfaE-8 probes, respectively (Mainil et al., 2000; Gérardin et al., 2000).

\section{Results}

\subsection{Prevalence of adhesin-encoding genes}

Two hundred and thirty-five $(14.7 \%)$ of the $1601 \mathrm{E}$. coli of the collection tested positive with the F17, Afa, Sfa and/or Eae probes, and none with the F18, Cs31A, Aidal and Bfp probes. 
Table 1

Origin (host, isolation site) of 408 probe-positive avian E. coli with case history

\begin{tabular}{|c|c|c|c|c|c|c|c|c|c|c|c|c|}
\hline \multirow[t]{3}{*}{ Probes } & \multicolumn{9}{|l|}{ Host/site } & \multicolumn{3}{|c|}{ Total (971) } \\
\hline & \multicolumn{3}{|c|}{ Chicken $(528)^{\mathrm{a}}$} & \multicolumn{3}{|c|}{ Turkey (332) } & \multicolumn{3}{|c|}{ Duck (111) } & \multirow[t]{2}{*}{ E (763) } & \multirow[t]{2}{*}{ I (208) } & \multirow[t]{2}{*}{$\%$} \\
\hline & $E^{b}(380)^{a}$ & $\mathrm{I}^{\mathrm{c}}(148)$ & $\%$ & $\mathrm{E}(272)$ & I (60) & $\%$ & $\mathrm{E}(111)$ & I $(0)$ & $\%$ & & & \\
\hline F17 & $28^{\mathrm{d}}$ & 0 & $5.3^{\mathrm{e}}$ & 23 & 1 & 7.2 & 8 & 0 & 8.0 & 59 & 1 & 6.2 \\
\hline Afa & 15 & 8 & 4.3 & 21 & 0 & 6.3 & 9 & 0 & 8.1 & 45 & 8 & 5.5 \\
\hline Sfa & 22 & 1 & 4.3 & 17 & 1 & 5.4 & 2 & 0 & 1.8 & 41 & 2 & 4.4 \\
\hline $\mathrm{P}$ & 139 & 23 & 30.7 & 102 & 2 & 31.3 & 23 & 0 & 20.7 & 264 & 25 & 29.8 \\
\hline Eae & 6 & 4 & 1.8 & 2 & 0 & $<1$ & 1 & 0 & $<1$ & 9 & 4 & 1.3 \\
\hline Total & 194 & 36 & 43.6 & 140 & 3 & 43.1 & 35 & 0 & 31.5 & 369 & 39 & 42.0 \\
\hline
\end{tabular}

Sixty-four E. coli (4.0\%) gave a strong positive signal and 57 (3.6\%) a weak positive signal with the F17 probe compared to the positive control strain. The F17-family PCR was subsequently applied on these $121 \mathrm{E}$. coli and gave positive results with 75 (4.7\%) of them. Only these 75 strains were further studied. Seventy-five strains $(4.7 \%)$ of the collection tested positive with the Afa probe, 67 (4.2\%) with the Sfa probe and $23(1.4 \%)$ with the Eae probe. Finally, 383 strains $(23.9 \%)$ were positive with the Pap probe.

Complete case histories were available for 408 probe-positive strains (Table 1). The strains isolated from chickens (528) and turkeys (332) were more frequently probe-positive (43.6 and $43.1 \%$, respectively) than those isolated from ducks (111,31.5\% probe-positive), as were the extraintestinal strains $(763,48.4 \%$ probe-positive) compared to the intestinal strains (208, 18.5\% probe-positive) (Table 1). Among groups of probe-positive strains, the majority also originated from extraintestinal organs: between $70 \%$ (Eae probe) and more than $99 \%$ (P probe) (Table 1).

\subsection{Subtyping of F17-, Afa- and Eae-positive E. coli}

The 75 F17-positive strains were subtyped using multiplex PCR for the a, b, c, and d variants of the $A$ gene: 52 strains (69.3\%) were f17Ac-positive, six strains $(8.0 \%)$ were f17Ac-and f17Ad-positive, four strains $(5.3 \%)$ were $f 17 \mathrm{Aa}$-positive, three strains $(4.0 \%)$ were f17Aa- and f17Ac-positive, three strains (4.0\%) were f17Ad-positive and seven strains $(9.3 \%)$ were not typeable. No positive result was obtained with the PCR for the F17b variant.

The PCR subtyping results of the $G$ gene were as follows: 36 strains (48.0\%) were $f 17 \mathrm{GII}$ and none f17GI (Table 2). Of the 39 strains $(52.0 \%)$ with no results by PCR, four $(5.3 \%)$ were positive with the F17GI probe and 20 (26.7\%) with the F17GII probe. Fifteen F17positive strains $(20.0 \%)$ were thus negative by PCR and by hybridisation for the $17 \mathrm{G}$ gene (Table 2). 
Table 2

Subtyping results of the $f 17 \mathrm{~A}$ and $f 17 \mathrm{G}$ genes of 75 F17 family PCR-positive $E$. coli

\begin{tabular}{|c|c|c|c|c|c|c|c|}
\hline \multirow{3}{*}{$\begin{array}{l}\text { f17A gene subtypes } \\
\text { (No. strains) }\end{array}$} & \multicolumn{7}{|c|}{ f17G gene subtyping } \\
\hline & \multicolumn{2}{|c|}{ f17GI } & \multicolumn{2}{|c|}{ f17GII } & \multicolumn{3}{|c|}{ No results } \\
\hline & PCR & Probe & PCR & Probe & PCR & Probe & $\mathrm{PCR}+$ probe \\
\hline f17Aa (4) & 0 & 4 & 0 & 0 & 4 & 0 & 0 \\
\hline f17Ac (52) & 0 & 0 & 29 & 41 & 14 & 2 & 9 \\
\hline f17Ad (3) & 0 & 0 & 1 & 1 & 0 & 0 & 2 \\
\hline f17Aa/f17Ad (3) & 0 & 0 & 0 & 2 & 2 & 0 & 1 \\
\hline f17Ac/f17Ad (6) & 0 & 0 & 1 & 5 & 4 & 0 & 1 \\
\hline No results (7) & 0 & 0 & 5 & 5 & 0 & 0 & 2 \\
\hline Total (75) & 0 & 4 & 36 & 54 & 24 & 2 & 15 \\
\hline
\end{tabular}

All 75 Afa-positive strains were confirmed as harbouring an afaE-8 gene and an additional one was detected by colony hybridisation with the AfaE- 8 specific probe. All 76 AfaE-8 probe-positive strains also tested positive with the PCR for the $a f a \mathrm{D}-8$ and afaE- 8 genes.

The 23 Eae-positive $E$. coli tested positive by the PCR for the $\beta$-variant (16 strains; $69.6 \%$ ) or for the $\gamma$-variant (seven strains; $30.4 \%$ ).

\subsection{Association between positive probe hybridisation results}

Different combinations of positive probe hybridisation results were observed (Table 3) in 72 of the 540 probe-positive E. coli (13.3\%). The most frequent combination was

Table 3

Combination of probes on the $540 \mathrm{E}$. coli positive strains by colony hybridisation

\begin{tabular}{llc}
\hline $\begin{array}{l}\text { Hybridisation } \\
\text { results }^{\text {a }}\end{array}$ & $\begin{array}{l}\text { No. of positive strains } \\
\text { (total of 540 strains) }\end{array}$ & $\begin{array}{l}\text { Percentage of } \\
\text { positive strains }\end{array}$ \\
\hline $\mathrm{P}$ & 351 & 65 \\
$\mathrm{~S}$ & 52 & 9.6 \\
AfaE-8 $/$ F17 & 37 & 6.9 \\
AfaE-8 & 24 & 4.4 \\
F17 & 22 & 4.1 \\
Eae & 19 & 3.5 \\
P/S & 11 & 2.0 \\
P/F17/AfaE-8 & 8 & 1.5 \\
P/F17 & 4 & $<1$ \\
AfaE-8/P & 4 & $<1$ \\
Eae/P & 3 & $<1$ \\
P/S/F17 & 2 & $<1$ \\
F17/AfaE-8/S & 2 & $<1$ \\
AfaE-8/Eae & 1 & $<1$ \\
\hline
\end{tabular}

\footnotetext{
${ }^{\text {a }}$ Only the F17 probe-positive strains confirmed by family PCR are presented.

${ }^{\mathrm{b}}$ One strain was negative with the Afa probe, but positive with AfaE- 8 probe.
} 
between AfaE-8 and F17 probes (47 strains; 8.7\%), in association with $\mathrm{P}$ or S probes in 10 strains, and the second most frequent combination was between $\mathrm{P}$ and $\mathrm{S}$ probes (13 strains; $2.4 \%$ ), in association with F17 probe in two strains. The other combinations accounted for less than $1 \%$ each (Table 3 ).

Thus, 468 positive E. coli $(86.7 \%)$ were positive with only one probe (Table 3 ): $\mathrm{P}$ (351 strains; 65\%), S (52 strains; 9.6\%), AfaE-8 (24 strains; 4.4\%), F17 (22 strains; 4.1\%) or Eae (19 strains; $3.5 \%$ ).

\subsection{Plasmid hybridisation}

Plasmid DNA was extracted from all 75 F17- and all 76 Afa-8-positive E. coli and hybridised with the F17 and AfaE-8 probes. No positive results were obtained except for the plasmids extracted from the positive controls.

\section{Discussion}

Although several E. coli strains are responsible for systemic infections in poultry, their virulence factors, in particular their adhesins and putative colonisation factors are unknown for most. According to the results obtained by DNA-DNA colony hybridisation on $1601 E$. coli isolated from internal organs and intestines of chickens, turkeys and ducks, Afa-VIII, F17, S (Sfa/F1C) and Intimin (Eae) adhesins may represent colonisation factors of some APEC, besides the well described P (Pap/Prs) fimbrial adhesins. All groups of probepositive $E$. coli were represented almost equally in chickens, turkeys and, to a lesser extent, ducks (Table 1). The presence and prevalence of pap/prs-related DNA sequences in E. coli from chickens and turkeys is no surprise according to previous results (Dho-Moulin and Fairbrother, 1999). On the other hand, Sfalfoc-,f17-, afa-, and eae-related DNA sequences have previously been described only in a few Algerian and Irish chicken E. coli (Gérardin et al., 2000; Mellata et al., 2001).

As expected, the majority of P-, S-, F17- and Afa-positive strains ( $>85 \%)$ originated from extraintestinal organs (Table 1), but the positive strains of intestinal origin emphasise once more the intestinal carriage of avian (putative) pathogenic E. coli (Dho-Moulin and Fairbrother, 1999). Subtyping identified the $f 17$ - and $a f a$-related DNA sequences present in avian $E$. coli as variants present in E. coli from mammals. The f17Ac and f17GII variants are the most frequent $f 17$ gene variants and the $a f a-8$ is the only afa variant present in avian E. coli, as previously observed for E. coli from mammals (Bertin et al., 1996b; Le Bouguénec and Bertin, 1999; Gérardin et al., 2000; Mainil et al., 2000). In contrast to mammalian E. coli in which the $f 17 \mathrm{c}$ and $a f a-8$ gene clusters can be plasmid-located (Mainil et al., 1997, 2000; Mainil, 1999; Gérardin et al., 2000), the f17- and afa-8-related DNA sequences are not plasmid-located in the poultry E. coli. No in vitro phenotypic assay was performed in this study, but the colony hybridisation and the subtyping results provide strong evidence for the presence of complete $f 17$ - and afa-8 gene clusters and thus for production of these adhesins. Indeed, several genes of the respective clusters were detected: f17A, $f 17 \mathrm{G}$ (at least in $60 \mathrm{E}$. coli) and part of $f 17 \mathrm{D}$ on the one hand; afaB, $a f a \mathrm{D}-8$ and $a f a \mathrm{E}-8$ on the other hand (Le Bouguénec and Bertin, 1999). 
Although the associations between the $f 17 \mathrm{~A}$ and $f 17 \mathrm{G}$ gene variants (f17Aa and $f 17 \mathrm{GI}$, $f 17 \mathrm{Ac}$ and $f 17 \mathrm{GII})$ are identical to those observed previously in mammalian $E$. coli (Bertin et al., 1996b), the detection and subtyping of f17-related sequences in variant E. coli calls for further comments. The 46 strains with weak hybridisation results and negative family PCR results may harbour new variant(s) of the $f 17$ gene clusters; similar results (Mainil et al., 1997) led to the description of the afa-7 and $a f a-8$ gene clusters in bovine $E$. coli (Lalioui et al., 1999). The strains with untypeable f17A and/or f17G genes (Table 2) may harbour new variants of these genes, as previous results already suggested (Bertin et al., 1996b). Alternatively the 15 strains with untypeable $f 17 \mathrm{G}$ genes may harbour incomplete $f 17$ gene clusters, as already observed for pap/prs gene clusters in APEC (Dho-Moulin and Fairbrother, 1999). The few strains positive for two f17A variants may actually harbour two $f 17$ gene clusters, as already observed for mammalian $E$. coli (Bertin et al., 1996b).

A few avian E. coli only were positive with the Eae probe derived from the eae gene. This one codes for the Intimin adhesin, which is part of the pathogenicity island called Locus of Enterocyte Effacement (LEE) of EPEC and EHEC and involved in the production of attaching/effacing (A/E) lesion (Nataro and Kaper, 1998). Several of them were recovered from intestinal sites, but the majority (65\%) were unexpectedly isolated from internal organs (Table 1). None were positive for the production of verotoxin (Blanco and Oswald, unpublished results) and all correspond to EPEC, rather than to EHEC, although they were negative with the Bfp probe derived from a gene cluster coding for an initial colonisation factor of human EPEC (Nataro and Kaper, 1998). It may thus be speculated that avian EPEC produce their own specific primary colonisation factor(s). PCR subtyping of the eae gene detected the $\beta$ - and the $\gamma$-variants, results similar to those obtained on a majority of EPEC and EHEC isolated from mammals (excluding man) (China et al., 1999a; Oswald et al., 2000; Goffaux et al., 2000). Presence of a complete LEE in these avian $E$. coli will be investigated using PCR assays for other LEE-located genes (China et al., 1999a).

Several associations among different gene clusters were observed between the pap/prsand the sfalfoc-, f17-, afa-8-, and/or eae-related DNA sequences. The most frequent association was actually between the $f 17$ - and $a f a-8$-related gene clusters (Table 3 ), as in NTEC2 strains from cattle (Mainil et al., 1997, 1999), although the poultry E. coli were non-NTEC (Blanco and Oswald, unpublished results). The presence of gene clusters coding for different adhesins is quite common in mammalian E. coli (Smyth et al., 1994), although the exact reason is not known. The expression of several adhesins by APEC would enhance their capability to colonise mucosae, perhaps even different mucosae, such as the intestine, which constitutes the reservoir, and the respiratory tract, which represents the entry site before invasion. This speculation needs confirmation with in vivo experiments.

F17, S fimbrial, Afa-VIII, and Intimin afimbrial adhesins may thus represent new virulence factors of APEC. Future experiments must be conducted to answer the following questions: (i) are these adhesins expressed in vitro and in vivo; (ii) are these E. coli specific pathogens for chickens, turkeys or ducks, after inoculation into the respiratory or intestinal tracts; and (iii) are these adhesins specific poultry colonisation factors for the respiratory or intestinal tracts. 
In vitro (with genetic and phenotypic assays, immunological assays and cell cultures) and in vivo (with ligated intestinal loop assays and tracheal challenge in young chickens, turkeys or ducks) studies with wild-type and allelic mutants will bring answers to these three questions.

\section{Acknowledgements}

The authors would like to thank Mrs. Vinciane Pirson and Mr. Etienne Jacquemin from the University of Liège (Belgium), Mrs. Annie Brée from the INRA (Tours, France) and Mrs. Anne-Soizic Guillon de Princé from Sanders Aliments (Laval, France) for their technical help in the collection, maintenance or typing of the strains. This work was financially supported by a grant from the Commission of the European Communities (Contract FAIR6-CT-98-4093).

\section{References}

Adu-Bobie, J., Frankel, G., Bain, C., Goncalves, A.G., Trabulsi, L., Douce, G., Knutton, S., Dougan, G., 1998. Detection of intimins $\alpha, \beta, \gamma$, and $\delta$, four intimin derivatives expressed by attaching and effacing microbial pathogens. J. Clin. Microbiol. 36, 662-668.

Babai, R., Blum-Oehler, G., Stern, B.E., Hacker, J., Ron, E.Z., 1997. Virulence patterns from septicemic Escherichia coli O78 strains. FEMS Microbiol. Lett. 149, 99-105.

Benz, I., Schmidt, A., 1989. Cloning and expression of an adhesin (AIDA-1) involved in diffuse adherence of enteropathogenic Escherichia coli. Infect. Immun. 57, 1506-1511.

Bertels, A., Pohl, P., Schlicker, C., Van Driessche, E., Charlier, G., de Greve, H., Lintermans, P., 1989. Isolation of F111 fimbrial antigen on the surface of a bovine Escherichia coli isolated from a calf diarrhea: characterization and discussion of the need to adapt recent vaccines against neonatal calf diarrhea. V1. Diergneesk. Tijdschr. 58, 118-122.

Bertin, Y., Girardeau, J.P., Darfeuille-Michaud, A., Contrepois, M., 1996a. Characterization of 20K, a new adhesin of septicemic and diarrhea-associated Escherichia coli strains, that belongs to a family of adhesins with $\mathrm{N}$-acetyl-D-glucosamine recognition. Infect. Immun. 64, 332-342.

Bertin, Y., Martin, C., Oswald, E., Girardeau, J.P., 1996b. Rapid and specific detection of F17-related pili and adhesin genes in diarrheic and septicemic Escherichia coli strains by multiplex PCR. J. Clin. Microbiol. 34, 2921-2928.

Blanco, J.E., Blanco, M., Mora, A., Jansen, W.H., Garcia, V., Vasquez, M.L., Blanco, J., 1998. Serotypes of Escherichia coli isolated from septicaemic chickens in Galicia (Northwest Spain). Vet. Microbiol. 61, 229-235.

Blum, G., Falbo, V., Caprioli, A., Hacker, J., 1995. Gene clusters encoding the cytotoxic necrotizing factor type 1, Prs-fimbriae and alpha-hemolysin form the pathogenicity island II of the uropathogenic Escherichia coli strain J96. FEMS Microbiol. Lett. 126, 189-195.

Broes, A., Fairbrother, J.M., Mainil, J.G., Harel, J., Lariviere, S., 1988. Phenotypic and genotypic characterization of enterotoxigenic Escherichia coli serotype O8, KX105 and O8, K2829 strains isolated from piglets with diarrhea. J. Clin. Microbiol. 26, 2402-2409.

China, B., Goffaux, F., Pirson, V., Mainil, J., 1999a. Comparison of eae, tir, espA and espB genes of bovine and human attaching and effacing Escherichia coli by multiplex polymerase chain reaction. FEMS Microbiol. Lett. 178, 177-182.

China, B., Jacquemin, E., Pirson, V., Devrin, A.C., Mainil, J., 1999b. Heterogeneity of the eaeA genes in attaching/effacing Escherichia coli from cattle: comparison with human strains. Res. Microbiol. 150, $323-332$. 
Dho-Moulin, M., Fairbrother, J.M., 1999. Avian pathogenic E. coli (APEC). Vet. Res. 30, 299-316.

Donnenberg, M.S., Welch, R.A., 1996. Virulence determinants of uropathogenic Escherichia coli. In: Mobley, H.L.T., Warren, J.W. (Eds.), Urinary Tract Infections: Molecular Pathogenesis and Clinical Management. ASM Press, pp. 135-174.

Dozois, C.M., Fairbrother, J.M., Harel, J., Bosse, M., 1992. pap- and pil-related DNA sequences and other virulence determinants associated with Escherichia coli isolated from septicemic chickens and turkeys. Infect. Immun. 60, 2648-2656.

El Mazouari, K., Oswald, E., Hernalsteens, J.P., Lintermans, P., de Greve, H., 1994. F17-like fimbriae from an invasive Escherichia coli strain producing cytotoxic necrotizing factor type 2 toxin. Infect. Immun. 62, 2633-2638.

Ellis, M.G., Arp, L.H., Lamont, S.J., 1988. Serum resistance and virulence of Escherichia coli isolated from turkeys. Am. J. Vet. Res. 49, 2034-2037.

Gérardin, J., Lalioui, L., Jacquemin, E., Le Bouguénec, C., Mainil, J.G., 2000. The afa-related gene cluster in necrotoxigenic and other Escherichia coli from animals belongs to the afa-8 variant. Vet. Microbiol. 76, 1-10.

Giron, J.A., Donnenberg, M.S., Martin, W.C., Jarvis, K.G., Kaper, J.B., 1993. Distribution of the bundle-forming pilus structural gene (bfpA) among enteropathogenic Escherichia coli. J. Infect. Dis. 168, 1037-1041.

Goffaux, F., Janssen, L., Jacquemin, E., China, B., Mainil, J., 2000. Genotypic characterization of enteropathogenic Escherichia coli (EPEC) isolated in Belgium from dogs and cats. Res. Microbiol. 151, $865-871$.

Gross, W.G., 1994. In: Gyles, C.L. (Ed.), Diseases due to Escherichia coli in Poultry. CAB International, Wallingford, pp. 237-259.

Imberechts, H., Van Pelt, N., De Greve, H., Lintermans, P., 1994. Sequences related to the major subunit gene fedA of F107 fimbriae in porcine Escherichia coli that express adhesive fimbriae. FEMS Microbiol. Lett. 3, 309-314.

Jerse, A.E., Yu, J., Tall, B.D., Kaper, J.B., 1990. A genetic locus of enteropathogenic Escherichia coli necessary for the production of attaching and effacing lesions on tissue culture cells. Proc. Natl. Acad. Sci. USA 87, 7839-7843.

Johnson, J.R., 1997. Urinary tract infection. In: Sussman, M. (Ed.), Escherichia coli-Mechanisms of Virulence. Cambridge University Press, Cambridge, pp. 495-549.

Lafont, J.P., Dho-Moulin, M., D’Hauteville, H.M., Bree, A., Sansonetti, P.J., 1987. Presence and expression of aerobactin genes in virulent strains of Escherichia coli. Infect. Immun. 55, 193-197.

Lalioui, L., Jouve, M., Gounon, P., Le Bouguénec, C., 1999. Molecular cloning and characterization of the afa-7 and afa-8 gene clusters encoding afimbrial adhesins in Escherichia coli strains associated with diarrhea or septicemia in calves. Infect. Immun. 67, 5048-5059.

Le Bouguénec, C., Bertin, Y., 1999. AFA and F17 adhesins produced by pathogenic Escherichia coli strains in domestic animals. Vet. Res. 30, 317-342.

Le Bouguénec, C., Archambaud, M., Labigne, A., 1992. Rapid and specific detection of the pap, afa, and sfa adhesin-encoding operons in uropathogenic Escherichia coli strains by polymerase chain reaction. J. Clin. Microbiol. 30, 1189-1193.

Lintermans, P., Pohl, P., Deboeck, F., Bertels, A., Charlier, G., Vandekerckove, J., Van Damme, J., Schoup, J., Schlicker, C., Korhonen, T., De Greve, H., Van Montagu, M., 1988. Characterization and purification of the F17 adhesin on the surface of bovine enteropathogenic and septicemic Escherichia coli. Am. J. Vet. Res. 49, 1794-1799.

Mainil, J., 1999. Shiga/verocytotoxins and shiga/verotoxigenic Escherichia coli in animals. Vet. Res. 30, 235-258.

Mainil, J.G., Jacquemin, E., Hérault, F., Oswald, E., 1997. Presence of pap-, sfa-, and afa-related sequences in necrotoxigenic Escherichia coli isolates from cattle: evidence for new variants of the AFA family. Can. J. Vet. Res. 61, 193-199.

Mainil, J.G., Jacquemin, E., Pohl, P., Fairbrother, J.M., Ansuini, A., Le Bouguénec, C., Ball, H.J., De Rycke, J., Oswald, E., 1999. Comparison of necrotoxigenic Escherichia coli from farm animals and from humans. Vet. Microbiol. 70, 123-135.

Mainil, J.G., Gérardin, J., Jacquemin, E., 2000. Identification of the F17 fimbrial subunit- and adhesin-encoding ( $f 17 \mathrm{~A}$ and $f 17 \mathrm{G})$ gene variants in necrotoxigenic Escherichia coli from cattle, pigs and humans. Vet. Microbiol. 73, 327-335. 
Martin, C., Boeuf, C., Bousquet, F., 1991. Escherichia coli CS31A fimbriae: molecular cloning, expression and homology with the K88 determinant. Microb. Pathog. 10, 429-442.

Mellata, M., Bakour, R., Jacquemin, E., Mainil, J., 2001. Genotypical and phenotypical characterization of potential virulence of intestinal avian Escherichia coli strains isolated in Algeria. Avian Dis. 45, 670-679.

Nagy, B., Fekete, P.Zs., 1999. Enterotoxigenic Escherichia coli in farm animals. Vet. Res. 30, $259-284$.

Nataro, J.P., Kaper, J.B., 1998. Diarrheagenic Escherichia coli. Clin. Microbiol. Rev. 11, 142-201.

O’Brien, A.D., LaVeck, G.D., Thompson, M.R., Formal, S.B., 1982. Production of Shigella dysenteriae type 1like cytotoxin by Escherichia coli. J. Infect. Dis. 146, 763-769.

Oswald, E., Scmidt, H., Morabito, S., Karch, H., Marchès, O., Caprioli, A., 2000. Typing of intimin genes in human and animal enterohemorrhagic and enteropathogenic Escherichia coli: characterization of a new intimin variant. Infect. Immun. 68, 64-71.

Oyetunde, O.O.F., Thomson, R.G., Carlson, H.C., 1978. Aerosol exposure of ammonia, dust and Escherichia coli in broiler chickens. Can. Vet. J. 19, 187-193.

Parreira, V.R., Arns, C.W., Yano, T., 1998. Virulence factors of avian Escherichia coli associated with swollen head syndrome. Avian Pathol. 27, 148-154.

Smyth, C.J., Marron, M., Smith, S.G.J., 1994. Fimbriae of Escherichia coli. In: Gyles, C.L. (Ed.), Escherichia coli in Domestic Animals and Humans. CAB International, Wallingford, pp. 399-435. 